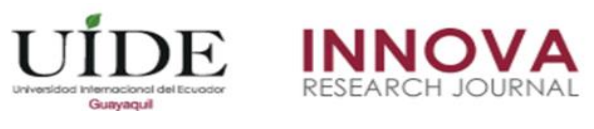

INNOVA Research Journal, ISSN 2477-9024

(Octubre, 2017). Vol. 2, No.10.1 pp. 36-41

DOI: https://doi.org/10.33890/innova.v2.n10.1.2017.485

URL: http://revistas.uide.edu.ec/index.php/innova/index

Correo: innova@uide.edu.ec

\title{
El poder del posicionamiento. Caso Nirsa
}

\section{The power of positioning. Nirsa case}

Lcda. Lorraine Chedraui A. MdB.

Universidad Ecotec, Ecuador

Autor para correspondencia: tochedra@hotmail.com - 1chedraui@ecotec.edu.ec

Fecha de recepción: 02 de Agosto de 2017 - Fecha de aceptación: 10 de Agosto de 2017

\section{Resumen}

El objetivo de este artículo es valorar la importancia de generar posicionamiento de la marca a partir del estudio del caso Nirsa de Guayaquil -Ecuador, con sus productos de atún enlatado de la marca Real. Se realizó una investigación documental y una entrevista al Gerente de Ventas de la empresa Nirsa. Los principales resultados obtenidos fueron que, al difundir los beneficios de un producto y resaltar sus características más sobresalientes, definen el lugar distintivo en el mercado y convierten a la marca en la base sólida de la ventaja competitiva, esto contribuye al incremento de las ventas, fortalecimiento de la reputación de una marca, y ayuda a introducir nuevas líneas de productos en el mercado con más facilidad.

Palabras claves: posicionamiento; marca; ventaja competitiva

\begin{abstract}
Abstact
The objective of this article is to evaluate the importance of generating brand positioning based on the analysis of the Nirsa case of Guayaquil -Ecuador, with its canned tuna products of the Real brand. A documentary research and an interview with the Sales Manager of the company Nirsa were carried out. The main results obtained were as follows: the benefits of the product and highlight its most outstanding characteristics, define the distinctive place in the market and make the brand a solid basis of competitive advantage, this contributes to increased sales, of the reputation of a brand, and helps new product lines in the market more easily
\end{abstract}

Key words: positioning; brand; competitive advantage 


\section{Introducción}

La palabra posicionamiento fue popularizada por los publicistas Ries y Trout quienes la definieron como el proceso de posicionar el producto en la mente de los consumidores, pero a través de los años este concepto fue ampliado y fue sumando nuevas características como las que establecieron Lambin y Galluci (2009): "La decisión de la empresa de elegir el o los beneficios que la marca debe presentar para ganar un lugar distintivo en el mercado" (p.254).

"El consumidor logra tener una percepción de un producto, marca o empresa, la cual la fija en la mente y de esta manera logra diferenciar ese producto, marca o empresa con respecto a la competencia" (Valls, 2014, p.87). Detrás de cada gran marca hay un posicionamiento claro, que es la razón por la que un cliente elige una marca sobre otra, y requiere análisis, creatividad y estrategia para establecer sus cimientos.

A través del estudio del caso Nirsa vamos a analizar la aplicación de su estrategia de posicionamiento de su marca Real, en el mercado ecuatoriano. El cual resultó muy eficaz porque los encaminó a liderar el mercado de los productos de atún enlatado, y desplazó a su competidor directo "INEPACA", que en ese entonces era quien lideraba el mercado. Por lo que este estudio nos da una visión más clara de lo que es posicionar a través de las diferenciaciones, los resultados positivos y a largo plazo que se pueden recoger al establecer una propuesta bien elaborada.

El objetivo de este artículo es establecer la importancia de generar posicionamiento de la marca, para ganar un lugar distintivo en el mercado, y convertirla en la base sólida de la ventaja competitiva, y se realizará a través del estudio de caso Nirsa.

\section{La marca Real}

\section{Desarrollo}

Negocios Industriales Real S.A. "N.I.R.S.A" es una compañía ecuatoriana, que fue fundada en el año de 1957, por el Sr. Julio Aguirre, quien llevó a cabo uno de sus sueños el cual fue constituir una planta para procesar sardinas en conservas. Al pasar de los años, el negocio se fue expandiendo y en 1988, para continuar con su crecimiento establece su nueva planta atunera y define su misión: "Ser líderes en el mercado de atún y sardinas, a través de una excelente calidad y un servicio personalizado" (Nirsa, 2017).

Pero desde el año 1949 la empresa INEPACA comercializaba atún con su marca Van Camps, liderando en el mercado durante las décadas venideras. Entonces, ¿Qué hizo Nirsa para posicionarse en el mercado con su producto estrella atún Real y cuál fue el proceso que siguió para ampliar su cartera de productos?

Nirsa ha invertido esfuerzo e importantes sumas de dinero en la elaboración, comercialización y difusión de los productos que maneja con marca REAL, dando lugar a que goce de prestigio y reconocimiento del público consumidor. Actualmente, "es uno de los principales exportadores de conservas de atún del Ecuador llegando a más de 25 países alrededor del mundo con sus productos" (Nirsa, 2017). 


\section{Posicionamiento}

La modalidad clásica de posicionar una marca es difundiendo los beneficios del producto para resaltar las características más sobresalientes, estableciendo así la diferenciación. "Una marca es percibida por un comprador potencial como un conjunto de atributos y de asociaciones mentales" (Lambin, Galluci, Sicurello, 2009, p.338). Son los atributos los que van a influir en la decisión de compra.

"Para posicionar una marca se necesitan objetivos a corto plazo, y definir lo que se va a comunicar, aumentar o reforzar en la promesa de la marca" (Aaker, 2014, p.123). Existen distintos modos de posicionar la marca frente a la competencia, entre ellos "la diferenciación de producto, la diferenciación de precio o la diferenciación de imagen (...) los clientes consideran varios atributos para evaluar la marca, los cuales pueden ser funcionales o tangibles, pero también pueden ser intangibles". (Lambin, Galluci, Sicurello, 2009, p.255).

Además, Kottler y Pfoertsch (2008) exponen que "los empleados desempeñan una función vital en la influencia, que son capaces de actuar sobre la confianza del cliente y la reputación corporativa, por lo que se debe construir desde adentro una marca interna fuerte, para ofrecer beneficios reales" (p120).

\section{Ventaja Competitiva}

"Una ventaja competitiva constituye una destreza o habilidad especial que logra desarrollar una empresa y que la coloca en una posición de preferencia a los ojos del mercado" (Koenes, 1997, p.21). Constituye un factor diferencial que hace que los clientes perciban como únicas las carácteristicas del producto o servicio.

Las ventajas competitivas deben estar basadas en provocar preferencia y aportar una percepción de diferenciación y exclusividad, que permitan ser el factor determinante en el proceso de decisión de compra.

\section{Metodología}

El presente artículo tiene como objeto valorar la importancia del posicionamiento a partir del estudio del caso Nirsa, por lo que se realizó una investigación documental y una entrevista al Gerente de Ventas de la empresa Nirsa.

Luego de obtener los resultados y por medio de la aplicación del método inductivodeductivo, se fundamentaron teorías relevantes para la lógica de establecer al posicionamiento como base sólida de la ventaja competitiva de una marca.

\section{Resultados y discusión}

El contenido de la entrevista fue agrupado en espacios temporales, desde los primeros procesos de la empresa hasta llegar al punto de su éxito, para exponer los detalles del cambio. 


\section{Primeros procesos}

"Hace más de 50 años no existía la metodología de hacer investigaciones, Nirsa se visualizaba como un negocio de sardinas, sin metodologías definidas, donde primaba el feeling y el sense al momento de crear un producto o una campaña" (Gerente Comercial Nirsa, Comunicación personal, 29 septiembre del 2013).

\section{Cambio táctico}

“Con la administración de los hijos del Sr. Aguirre, hablamos de unos 10 años atrás hasta ahora, ya había una visión mucho más trabajada del negocio, para darle a la marca Real un valor agregado" (Gerente Comercial Nirsa, Comunicación personal, 29 septiembre del 2013). Es el tiempo donde la marca Real preparaba su estrategia para innovar en el mercado.

\section{Estrategia y campaña exitosa}

"Fue el pionero del sistema abre fácil del atún" (Gerente Comercial Nirsa, Comunicación personal, 29 septiembre del 2013). Esta presentación innovadora del producto que surgió en el año 1997, generó expectativa, emoción y ayudó al prestigio de la marca, dándole mayor identidad, y transformó el concepto previo de "buen alimento, difícil apertura" a "buen alimento, fácil consumo", que además podía ser abierto por un niño sin temer a riesgos de lastimarse.

"Tras la estrategia revolucionaria de la forma de abrir una lata de atún, se lanza la campaña Tun tun tun tun atún Real, realmente atún" (Gerente Comercial Nirsa, Comunicación personal, 29 septiembre del 2013). La marca Real establece una posición definida en el mercado, estableciéndose como el único producto con easy open en el mercado, esto dio origen al descenso de la participación en el mercado de la marca INEPACA con su producto Van Can.

\section{Estrategia post éxito}

"La marca se diversificó, ofertando pescado remojado en distintos aceites" (Gerente Comercial Nirsa, Comunicación personal, 29 septiembre del 2013). Los atributos excitantes son tangibles, pero también tienden a tener poca vida, ya que la competencia los imita rápidamente, así que tras el éxito obtenido su siguiente estrategia fue expandir sus productos.

\section{Ventaja del posicionamiento}

"En estos últimos años, gracias a la fortaleza de la marca, la compañía ha empezado a introducir productos en otros segmentos, como jugos Real, arroz Real que es parte de la canasta básica, conservas enlatadas Real, como duraznos, coctel de frutas, congelados tales como pescado, camarón, empanadas y pan de yuca." (Gerente Comercial Nirsa, Comunicación personal, 29 septiembre del 2013). Podemos definir que tener un nombre fuerte puede ser, además de un valioso activo, el arma competitiva más eficaz para una compañía, por ello continuaron expandiendo sus productos.

\section{Procesos posteriores}


"NIRSA S.A., bajo el paraguas Real mantiene la idea de fortalecer la presencia de marca en otras categorías que sean atractivas para el consumidor final, ya que se considera que tienen una marca muy fuerte ... Hoy en día la idea es que cada categoría tenga un especialista de marca. Estas personas van a ir a la calle y comprar estudios de mercado, que se venden abiertamente y que te dan todos los detalles que necesitas para estructurar las estrategias" (Gerente Comercial Nirsa, Comunicación personal, 29 septiembre del 2013). Los mercados cambian constante y rápidamente, los clientes presentan cambios acorde con la evolución de las épocas, son sensibles al precio, a las características de un producto o servicio, a su calidad, entre otras, por lo que deben analizar el mercado y lanzar estrategias conforme a las necesidades del mercado. "Antes la compañía era el cazador en busca de clientes; ahora el consumidor se ha convertido en el cazador" (Kottler, Jain, Maesincee, 2002, p.14).

Luego de analizar la estrategia exitosa de la marca Real, se puede deducir el proceso para el posicionamiento de la marca en el siguiente gráfico:

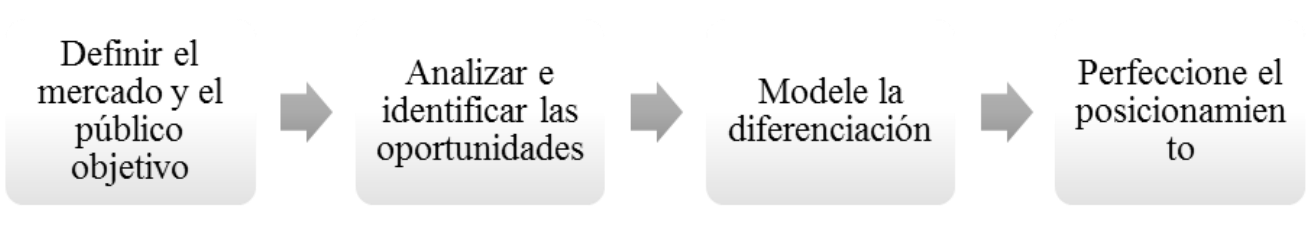

Gráfico 1: Proceso para generar posicionamiento Fuente: Elaborado por el autor

Es una premisa fundamental analizar el comportamiento del consumidor, para establecer el perfil, actitudes y preferencias del grupo objetivo. "Es recomendable comenzar recogiendo datos sobre las oportunidades de negocio, así como las necesidades del cliente y sus motivaciones del compra" (Brujó y Clifton, 2010). Sin esta información se estaría trabajando sin dirección y creando estrategias bajo suposiciones, hasta replicando lo que realiza la competencia, sin opción a sobresalir.

"Las empresas deben saber a dónde se dirigen según su plan de negocios y de marketing. Los antecedentes de la empresa, su historia y las tradiciones que se han creado son importantes para proyectar una imagen externa." (Ferro, 2011, p.50).

"Una marca debe tener una ventaja relevante a nivel funcional y emocional... las personas toman las decisiones movidas principalmente por razones emocionales y luego las justifican con razones lógicas" (Brujó y Clifton, 2010). Todo posicionamiento debe reflejar la cultura y personalidad de la empresa para establecer una credibilidad, debe diferenciarse de la competencia a la perfección, y presentarse como un desafío que sirva de motor para que aumente su rendimiento.

\section{Conclusiones}

La fortaleza de una marca es el resultado de la frecuencia de innovaciones, y las marcas poderosas pueden convertirse en la base sólida de la ventaja competitiva y de rentabilidad a largo plazo (Aaker, 2014, p.26). Nirsa logró destacarse y liderar en el mercado con su estrategia de 
diferenciación de producto "easy open", logrando un posicionamiento claro y definitivo, que se convirtió en la ventaja competitiva, lo cual le permitió ingresar en otros segmentos con gran facilidad.

La percepción de los clientes hacia una marca depende de la relevancia de los atributos elegidos, la experiencia adquirida, la influencia de los estereotipos existentes, el grado de necesidad y la comunicación recibida. Hay que identificar las características del público objetivo, identificar las claves del producto o marca en ese mercado, conocer los atributos con los que asocia el cliente, dibujar y decidir la posición deseada y como último establecer las acciones para conseguir esa posición.

Las marcas únicas también llamadas marcas paraguas tienen como ventaja todas las acciones de comunicación que se realicen en torno a su producto y si han sido eficaces repercutirán en todos los demás productos de la empresa. Esta estrategia permite una extensión de marca y ayuda a que los nuevos productos se introduzcan en los mercados con notoriedad y buena imagen. "La notoriedad es un grado superior al que llegan pocas marcas. Es una aspiración que los titulares marcarios siempre tienen. El lograr ese status implica un nivel de aceptación por parte del público que sólo es consecuencia del éxito que ha tenido el producto o servicio que las marcas distinguen" (Otamendi, 2006, p.363).

Existen algunos tipos de diferenciaciones, pero una buena estrategia de diferenciación de producto es fácil de comprender, ayuda a la notoriedad y la comunicación. Permite establecer una identidad, ayudándolos a construir una idea clara en la mente de los consumidores. Una vez posicionado el producto en el mercado se suma como una ventaja competitiva, ya que su nombre por si solo vende.

\section{Bibliografía}

Aeker, D. (2014). Las Marcas según Aeker. Barcelona, España: Ediciones Urano S.a.

Ferro, X. (2011). La Creación de una marca, Grandes marcas. Ekos Negocio , 50-57.

Otamendi, J. (2006). Derecho de marcas (6ta edición ed.). Buenos Aires, Argentina: Editorial Lexis Nexis.

Lambin, Galluci, \& Sicurello. (2009). Dirección de Marketing, gestión estratégica y operativa del mercado. México: McGraw Hill.

Kotler, P., \& Pfoertsch, W. (2008). Branding B2B, gestión de marcas para productos industriales. México: Grupo Editorial Patria S.A. de C.V.

Kotler, P., Jain, D., \& Maesincee S. (2002). El Marketing se mueve. Buenos Aires, Argentina: Paidós.

Valls, F. (2014). Estrategias y Tácticas de Marketing. Barcelona, España: Profit Editorial.

Nirsa. (15 de marzo de 2017). Recuperado de http://nirsa.com/home.php

Brujó, G., \& Clifton, R. (2014). En clave de marcas. Madrid, España: Lid Editorial Empresarial.

Koenes, A. (ed). (1997). La ventaja competitiva. Madrid, España: Ediciones Diaz Santos. 